\title{
Identidade cultural: comunidade indígena Kaingang do Município de Santa Maria,
}

\section{RS, Brasil}

\author{
Cultural identity: Kaingang indigenous community in the Municipality of Santa Maria, RS, Brazil \\ Identidad cultural: comunidad indígena Kaingang en la Ciudad de Santa Maria, RS, Brasil
}

Recebido: 16/03/2021 | Revisado: 23/03/2021 | Aceito: 02/04/2021 | Publicado: 04/04/2021

\author{
Márcia Eliana Migotto Araujo \\ ORCID: https://orcid.org/0000-0002-0014-4739 \\ Escola Estadual de Educação Básica Augusto Ruschi, Brasil \\ E-mail: meliana12003@yahoo.com.br \\ Liziany Müller Medeiros \\ ORCID: https://orcid.org/0000-0001-7325-6611 \\ Universidade Federal de Santa Maria, Brasil \\ E-mail: lizianym@hotmail.com \\ Juliane Paprosqui \\ ORCID: https://orcid.org/0000-0002-3034-2453 \\ Universidade Federal de Santa Maria, Brasil \\ E-mail: juliane_paprosqui@hotmail.com \\ Ivanio Folmer \\ ORCID: https://orcid.org/0000-0002-7433-6434 \\ Universidade Federal de Santa Maria, Brasil \\ E-mail: ivaniofolmer@yahoo.com.br \\ Gabriella Eldereti Machado \\ ORCID: https://orcid.org/0000-0001-5908-4753 \\ Universidade Federal de Santa Maria, Brasil \\ E-mail: gabriellaeldereti@gmail.com
}

\begin{abstract}
Resumo
A pesquisa tem por objetivo geral investigar a identidade cultural da comunidade indígena Kaingang residente na cidade de Santa Maria-RS, Brasil. Quanto aos objetivos específicos, busca-se realizar um resgate histórico das áreas do território brasileiro habitada pelos povos indígenas, pesquisar em sites e documentos legais informações sobre essas comunidades e descrever a identidade cultural da comunidade Kaingang residente na cidade de Santa Maria-RS. Para a realização do estudo, o instrumento utilizado foi uma pesquisa documental e bibliográfica, uma entrevista e um questionário aplicado com o cacique da tribo. Concluiu-se que a tribo kaingang busca preservar suas expressões culturais e também tenta dialogar com os poderes públicos para a resolução de conflitos. Esta tribo deseja seguir sua história, sua cultura e também sua inserção no mundo contemporâneo reflexivamente diante dos desafios impostos pela sociedade globalizada.
\end{abstract}

Palavras-chave: Kaingang; Santa Maria; Cultura; Indígena.

\begin{abstract}
The general objective of the research is to investigate the cultural identity of the Kaingang indigenous community residing in the city of Santa Maria-RS, Brazil. As for the specific objectives, we seek to carry out a historical rescue of the areas of the Brazilian territory inhabited by indigenous peoples, search websites and legal documents for information about these communities and describe the cultural identity of the Kaingang community residing in the city of Santa Maria-RS. For the accomplishment of the study, the instrument used was a documentary and bibliographic research, an interview and a questionnaire applied with the chief of the tribe. It was concluded that the Kaingang tribe seeks to preserve their cultural expressions and also tries to dialogue with public authorities for the resolution of conflicts. This tribe wishes to follow its history, its culture and also its insertion in the contemporary world reflexively in the face of the challenges imposed by the globalized society.
\end{abstract}

Keywords: Kaingang; Santa Maria; Culture; Indigenous.

\section{Resumen}

El objetivo general de la investigación es investigar la identidad cultural de la comunidad indígena Kaingang que reside en la ciudad de Santa Maria-RS, Brasil. En cuanto a los objetivos específicos, buscamos realizar un rescate histórico de las áreas del territorio brasileño habitadas por pueblos indígenas, buscar sitios web y documentos legales para obtener información sobre estas comunidades y describir la identidad cultural de la comunidad Kaingang que reside en la ciudad de Santa Maria-RS. Para la realización del estudio, el instrumento utilizado fue una investigación 
documental y bibliográfica, una entrevista y un cuestionario aplicado con el jefe de la tribu. Se concluyó que la tribu Kaingang busca preservar sus expresiones culturales y también intenta dialogar con las autoridades públicas para la resolución de conflictos. Esta tribu desea seguir su historia, su cultura y también su inserción en el mundo contemporáneo de manera reflexiva ante los desafíos impuestos por la sociedad globalizada.

Palabras clave: Kaingang; Santa María; Cultura; Indígena.

\section{Introdução}

De acordo com os dados do Instituto Brasileiro de Geografia e Estatística (IBGE), o ano de 2010 apresentou mais de 817 mil brasileiros que se intitularam como indígenas. Este resultado, comparado com pesquisas anteriores, revela um aumento considerável da população nas áreas urbanas do país, sendo a comunidade indígena Kaingang uma das cinco mais populosas do território brasileiro (Brasil)

Na análise da distribuição espacial dos indígenas revelada pelo censo 2010, observou-se que a região Norte e o ambiente amazônico mantêm a supremacia ao longo dos censos, com 37,4\% de declarações na categoria indígena. Outra questão importante consiste na redução sensível da participação de indígenas da região Sudeste, podendo-se atribuir, em parte, aos movimentos migratórios de retorno às suas terras e, também, à redução de declarações nas áreas urbanas. De um modo geral, para as regiões Sudeste e Sul, tanto na área urbana quanto na rural houve redução da participação de indígenas no total de indígenas do país, mais significativamente na região Sudeste. Dos indígenas que residem nas áreas urbanas, a maior participação $(33,7 \%)$ foi encontrada na região Nordeste, e nos residentes das áreas rurais, enquanto a região Norte historicamente manteve a maior concentração, com 48,6\%. (Pereira, 67 2010, p. 01)

O tema comunidades indígenas perpassa por diferentes pensamentos ideológicos e também partidários, haja vista que o Brasil é uma democracia partidária. Nesse sentido, essas questões influenciam diretamente as políticas públicas indígenas. Durante as últimas décadas, foram organizados movimentos em apoio às comunidades indígenas, porém, ainda, buscam-se conclusões apropriadas e definitivas para a satisfação tanto da comunidade indígena, quanto por parte da comunidade em geral.

A partir de movimentos e necessidades diversas, surgem as políticas públicas que auxiliam nos processos de demarcações de terras indígenas. Como, por exemplo, destacam-se os problemas e as dificuldades de adaptação dos indígenas. Quando as tribos indígenas são retiradas de seu lugar de morada ancestral, ocorre um comprometimento cultural desses povos. De acordo com Moacir Gadotti $(2018,02$.) "A sensação de pertencimento à Terra não se inicia na idade adulta e nem por um ato de razão. Desde a infância, sentimo-nos ligados com algo que é muito maior do que nós". Corroborando com os estudos de Yi Fu Tuan (1983) que caracteriza os lugares como centros nos quais são atribuídos valores e onde são satisfeitas as necessidades biológicas de comida, água, descanso e procriação.

De acordo com a Organização das Nações Unidas para a Educação, a Ciência e a Cultura - UNESCO, os direitos culturais são reconhecidos como "parte integrante dos direitos humanos, que são universais, indissociáveis e interdependentes", nestes estão presentes a criação e difusão cultural, a participação na vida cultural, o respeito às identidades e o livre exercício das práticas culturais (UNESCO, 2002).

O Brasil reconhece os direitos culturais e os apresenta no artigo 215 da Constituição de 1988, no qual afirma que "O Estado garantirá a todos o pleno exercício dos direitos culturais e acesso às fontes da cultura nacional, e apoiará e incentivará a valorização e a difusão das manifestações culturais" (Brasil, 1989).

Cultura é uma palavra de origem latina, colere, que significa "cultivar, criar, tomar conta, cuidar" (Chauí, 1997, p. 292) que por sua vez é uma ação marcada pelo cuidado. Como significado geral, cultura é a criação humana que ocorre nas relações entre as pessoas e dessas com a natureza, com o meio ambiente no qual se constrói os modos de vida. Estas relações entre as pessoas movem e transformam o mundo e, consequentemente, transformam-se a si mesmos. 
A população indígena no Brasil, ao longo dos séculos, enfrenta dificuldades sociais, econômicas e até mesmo culturais. Dados estatísticos da Fundação Nacional do Índio (FUNAI) reportam que desde o ano de 1500 até a década de 70 a população indígena sofreu uma redução considerável e com a extinção de alguns povos (Brasil).

Um importante órgão governamental brasileiro indigenista é a Fundação Nacional do Índio (FUNAI), esta fundação foi criada em 5 de dezembro de 1967, pela Lei n ${ }^{\circ}$ 5.371, vinculada ao Ministério da Justiça. Ela é responsável por coordenar e executar políticas indigenistas, além de ter por encargo institucional proteger e promover os direitos dos povos indígenas no Brasil.

Cabe à FUNAI promover estudos de identificação e delimitação, demarcação, regularização fundiária e registro das terras tradicionalmente ocupadas pelos povos indígenas, além de monitorar e fiscalizar as terras indígenas. A FUNAI também coordena e implementa as políticas de proteção aos povo isolados e recém-contatados. (Brasil)

A partir de 1991, o Instituto Brasileiro de Geografia e Estatística - IBGE estendeu suas pesquisas para com a população indígena no censo demográfico nacional. Nessas, os dados demonstraram um aumento de 150\% do número de brasileiros que se consideram indígenas, isso ocorreu na década de 90 . A taxa de indígenas em semelhança à população total brasileira aumentou de 0,2\% em 1991 para 0,4\% em 2000, resultando em 734 mil pessoas. Como decorrência, um aumento anual de $10,8 \%$ da população, constituindo-se o maior percentual de crescimento entre todas as categorias, em média um aumento de 1,6\% (Brasil, 2018).

O Gráfico 1 mostra alguns dados demográficos sobre a população indígena no Brasil, desde o ano de 1500 até 2010 apresentando informações das regiões do interior e do litoral.

Gráfico 1. Dados demográfico população indígena no Brasil.

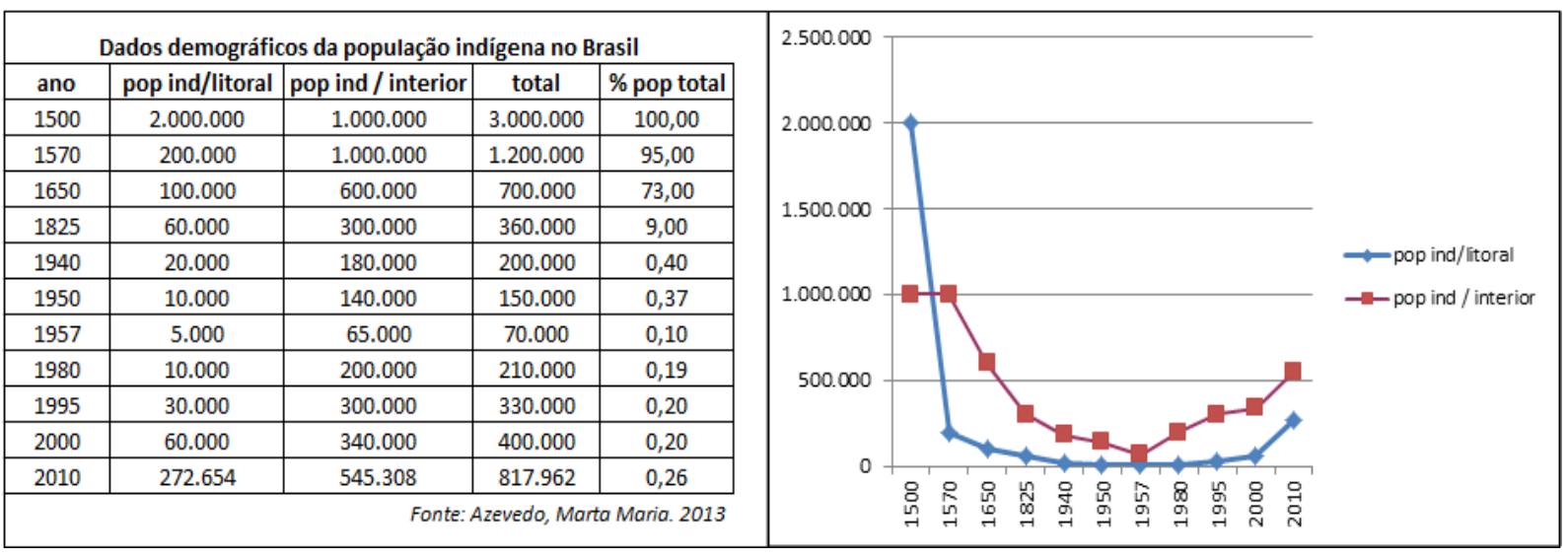

Fonte:_http://www.funai.gov.br/index.php/indios-no-brasil/quem-sao

Outra particularidade importante sobre os indígenas é o aumento desta população nas zonas rurais, de acordo com o censo demográfico realizado pelo IBGE no ano de 2010, foram apontados 817.963 indígenas, sendo que destes 502.783 vivem na zona rural e 315.180 residem nas zonas urbanas.

A relação do índio com a terra brasileira ao longo da história é combinada por conflitos sociais, políticos, econômicos e culturais.

Nos anos 1990, a garantia do direito originário dos povos indígenas às suas terras passou a se alicerçar sobre o estudo minucioso da territorialidade dos diferentes povos indígenas, considerando-se não apenas seus usos passados e presentes, mas também a perspectiva de uso futuro, tudo isso "segundo seus usos, costumes e tradições", conforme o artigo 231 do texto constitucional. (Brasil). 
As políticas públicas, para Marta Rodrigues (2010, p.14) são "resultantes da atividade política, requerem várias ações estratégicas destinadas a implementar os objetivos desejados". É importante que as políticas públicas possam efetivar-se na prática para que os povos indígenas tenham o que é seu por direito cultural institucional.

Gráfico 2. Distribuição da população indígena.

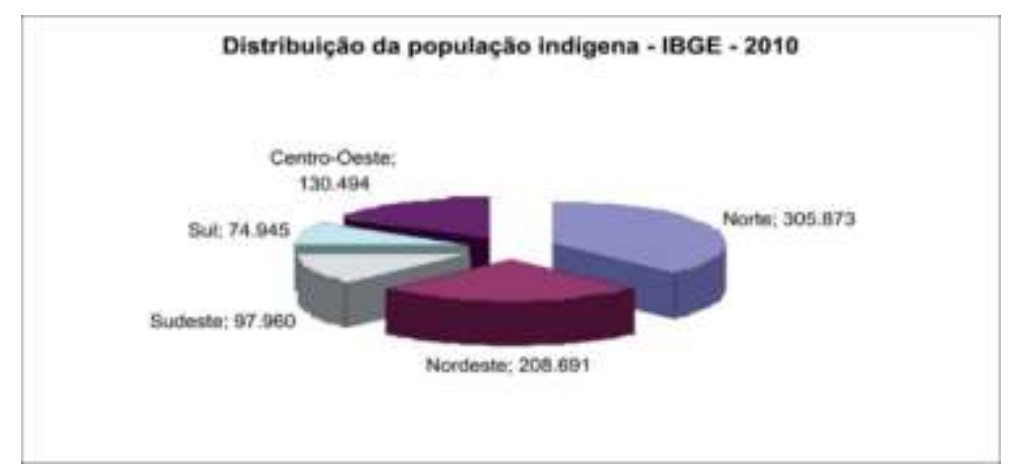

Fonte: http://www.funai.gov.br/index.php/indios-no-brasil/quem-sao

O Gráfico 2 está referendado no site da FUNAI, no qual também se apresenta alguns dados estáticos sobre a população indígena nos estados brasileiros, o censo foi realizado em 2010, neste a população brasileira soma 190.755.799 milhões de pessoas. Ainda, segundo o censo, 817.963 mil são indígenas, representando 305 diferentes etnias. Foram registradas no país 274 línguas indígenas e, também, evidenciou-se que cerca de 17,5\% da população indígena não fala a língua portuguesa.

Outra problemática existente em alguns Estados brasileiros são conflitos fundiários por contestações pela terra, atualmente, a sociedade em geral tem o desafio de promover as demarcações das terras indígenas. O gráfico 03 apresenta alguns dados por regiões do Brasil.

Gráfico 3. Demarcações de terras indígenas.

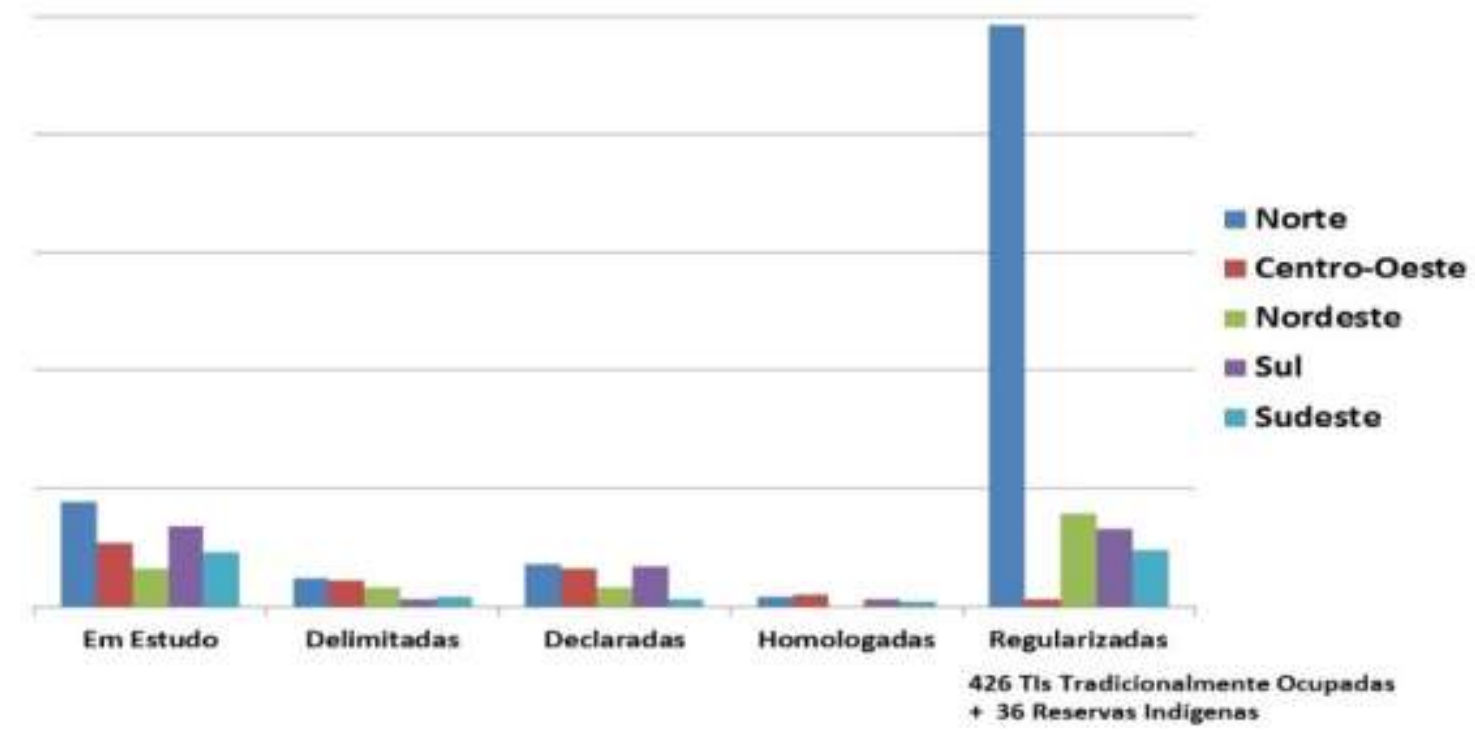

Fonte: http://www.funai.gov.br/index.php/nossas-acoes/demarcacao-de-terras-indigenas?start=2\# 
Segundo dados da FUNAI, o Gráfico 3 mostra que quase $8 \%$ das 426 terras indígenas tradicionalmente ocupadas e já regularizadas ainda não estão na posse integral das comunidades indígenas.

A busca por informações mais atuais, ou seja, posterior ao ano de 2010 no site do IBGE sobre as comunidades indígenas, não foi possível, pois os estudos estatísticos encontrados em sites, mais atuais referem-se ao ano de 2010.

\section{Metodologia}

O caminho metodológico percorrido pela pesquisa primeiramente, consistiu em uma pesquisa documental e bibliográfica sobre as tribos indígenas no Brasil, realizada através de uma mineração de dados a partir de sítios eletrônicos sobre o assunto para o entendimento de como a população indígena está organizada bem como quais suas etnias, etc, o que permitiu o embasamento teórico da pesquisa. Posteriormente, buscou-se conhecer in loco a tribo Kaingang, localizada na cidade de Santa Maria-RS que localiza-se no centro geográfico do Rio Grande do Sul a $29^{\circ} 42^{\prime}$ de latitude sul e a $53^{\circ} 42^{\prime}$ de longitude oeste. O clima é temperado, com o aparecimento de nevoeiros e, em média, a precipitação anual é de $1732 \mathrm{~mm}$, a temperatura média varia entre $18^{\circ} \mathrm{C}$ e $20^{\circ} \mathrm{C}$ (NIMER, 1977).

Para conhecer a aldeia foi realizada visitação com observação não participante, que para Marconi e Lakatos (1996, p.79) auxilia o pesquisador a "[..] identificar e obter provas a respeito de objetivos sobre os quais os indivíduos não têm consciência, mas que orientam seu comportamento" buscou-se desta forma o entendimento de como a comunidade estava organizada, quantas famílias residiam na aldeia, quais seus meios de subsistência, etc. Neste momento também foi aplicado um questionário e uma entrevista semi-estruturada ao cacique da aldeia, as quais versavam sobre o modos de vida, cultura e subsistência da tribo. Com a observação, a aplicação do questionário e a entrevista, a pesquisa se caracterizou no terceiro e último momento dentro de uma abordagem qualitativa, pois, essa análise é "uma tentativa de se explicar em profundidade o significado e as características do resultado das informações obtidas através de entrevistas ou questões abertas" (OLIVEIRA 2012, p. 59) sendo caracterizada também como uma pesquisa de campo, que, segundo Gil (2008), no estudo de campo, estudase um único grupo ou comunidade em termos de sua estrutura social, ou seja, ressaltando a interação de seus componentes.

\section{Resultados}

A comunidade Kaingang, conhecida como Aldeia Três Soitas, atualmente (novembro de 2018), localiza-se na cidade de Santa Maria, na Rua Pedro Santini, no bairro Nossa Senhora de Lourdes, e é comandada pelo cacique Natanael Claudino. Moram, na aldeia, 21 famílias, totalizando 76 pessoas, sendo 42 adultos e, entre jovens e crianças, somam 34, dados revelados pelo questionário aplicado.

A Escola Kaingang iniciou suas atividades no ano de 2013, com nome de "Escola Estadual de Ensino Fundamental Augusto Opê da Silva”, este nome é uma homenagem ao líder indígena da região sul do Brasil. A escola iniciou suas atividades com dificuldades devido as condições precárias de funcionamento, estruturais e de falta de professores habilitados.

Atualmente, estão matriculados na escola da tribo 36 alunos. De acordo com o Cacique Natanael, o número de alunos aumenta nas datas comemorativas (Páscoa e Natal), período em que famílias de outras regiões vêm para Santa Maria venderem suas produções e artesanatos.

No total, três alunos já concluíram o Ensino Médio e, atualmente a tribo conta com 4 jovens cursando o Ensino Médio, na Escola Estadual de Educação Básica Irmão José Otão.

Nas palavras do Cacique Natanael:

A nossa escola quando criada... a ideia era preservar a língua, a nossa cultura, falar da nossa cultura envolve o uso da medicina tradicional, uso dos cantos, uso das danças tradicionais, revitalizar, fortalecer essas culturas que ta viva em 
nós... então muitos que não conheciam a forma de nos organizar como comunidade indígena (...) quando nós criamos a escola era pra primeiro ensinar o português depois o kaingang e nós fizemos o contrário... primeiros vamos alfabetizar nossas crianças no kangang, vamos adotar o português como segunda língua, hoje nossas crianças são alfabetizadas primeiro no kaingang, no terceiro e quarto ano o português.

No mês de novembro de 2018, a escola conta com "12 alunos pequenos, só os pequenininhos... que falam só Kaingang”, segundo o Cacique. A escola conta com uma professora indígena, que ensina língua kaingang, na Educação Infantil, e possui formação em magistério, além de residir na tribo.

Para o lingüista Aryon Dall'Igna Rodrigues, a língua kaingang pertence à família jê do tronco macro-jê. Já a lingüista e missionária do SIL (Summer Institute of Linguistics), Ursula Wiesemann, classificou a língua dos Kaingang atuais em cinco dialetos:

(1) de São Paulo (SP), entre os rios Tietê e Paranapanema; (2) do Paraná (PR), entre os rios Paranapanema e Iguaçu; (3) Dialeto Central (C), entre os rios Iguaçu e Uruguai, Estado de Santa Catarina; (4) Dialeto Sudoeste (SO), ao sul do rio Uruguai e a oeste do rio Passo Fundo, Estado do Rio Grande do Sul; e (5) o Dialeto Sudeste (SE), ao sul do rio Uruguai e leste do rio Passo Fundo. (Wieessemann, 2018)

A escola da tribo Kaingang da cidade de Santa Maria-RS, dentre suas metodologias, está a tarefa de ensinar a língua kaingang originária da família linguística Jê e a língua Portuguesa. O alfabeto Kaingang é constituído pelas vogais: A Á Ã E É Ẽ I Ĩ O Ó U Ũ Y Ỹ e pelas consoantes: F G H J K M N NH P R S T V. Existe uma preocupação com a educação e a identidade cultural para a valorização com as gerações futuras.

A cultura contribui para a formação de padrões de alfabetização na qual estão presentes as narrativas (locais e nacionais) históricas, literárias, etc. Essas questões estão sendo ponderadas para auxiliarem na composição de políticas públicas, locais, regionais e nacionais. Uma cultura nacional pode vir a ser uma estrutura de poder cultural e, por isso, as manifestações culturais não podem ser apagadas, nem ignoradas, pois estas fazem parte do indivíduo, segundo a Funai;

Os Povos Indígenas têm direito a uma educação escolar específica, diferenciada, intercultural, bilíngue/multilíngue e comunitária, conforme define a legislação nacional que fundamenta a Educação Escolar Indígena. Seguindo o regime de colaboração, posto pela Constituição Federal de 1988 e pela Lei de Diretrizes e Bases da Educação Nacional (LDB), a coordenação nacional das politicas de Educação Escolar Indígena é de competência do Ministério da Educação (MEC), cabendo aos Estados e Municípios a execução para a garantia deste direito dos povos indígenas. (Brasil, 2018)

Um exemplo de proposta educacional indígena é a revista em quadrinhos "As aventuras do indiozinho Bretã", (Figura 01) que foi criada e lançada no dia 26 de setembro de 2013 e apresenta histórias contadas pelas próprias crianças da aldeia Três Soitas (Carvalho, 2013). 
Figura 1. Revista em quadrinhos "Bretã".

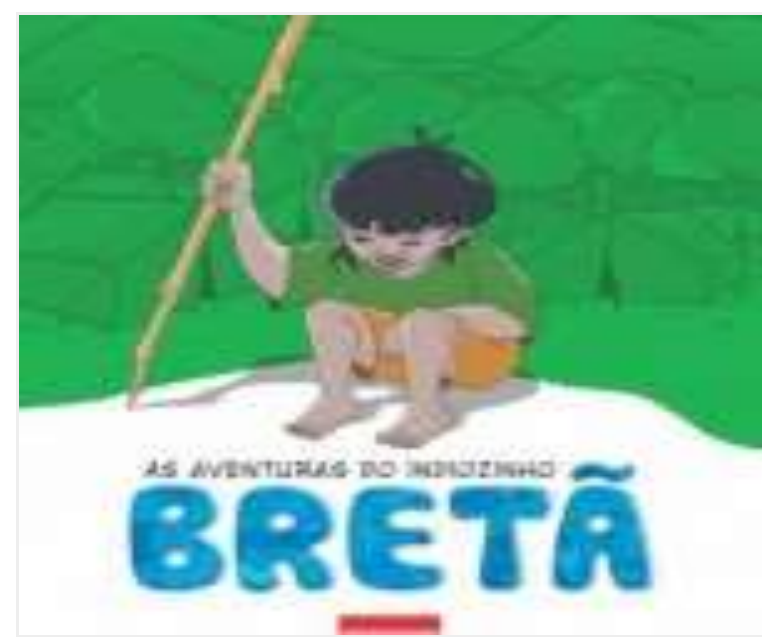

Fonte: http://centralsul.org/2013/kaingang-o-indio-em-santa-maria/

A revista em quadrinhos é bilíngüe (escrita em língua portuguesa e kaingang) pretende ser para os leitores um material de aprendizagem. Estão presentes na obra histórias que mostram a influência mútua dos valores de uma criança indígena com o dia a dia de uma sociedade em que o índio, muitas vezes, é vítima de visões preconceituosas (Carvalho, 2013)

\section{1 acesso ao ensino superior}

Atualmente, no Brasil, existem políticas públicas específicas para os indígenas, no ano de 2014 aprovou-se o Plano Nacional de Educação - PNE pela então presidenta Dilma Rousseff e, neste plano, a educação escolar indígena está incluída na educação para a diversidade. Nas palavras de Rita Potiguara "O PNE traz um aspecto importante, que é a afirmação da necessidade de que a gestão da educação escolar indígena ocorra por meio dos territórios etnoeducacionais".

A potiguara Rita Gomes do Nascimento, diretoria de Políticas de Educação do Campo, Indígena e para as Relações Étnico-Raciais, no Ministério da Educação, foi a primeira mulher indígena a trabalhar em uma diretoria na Esplanada dos Ministérios. É professora doutora ocupante de uma cadeira na Câmara de Educação Básica do Conselho Nacional de Educação (CNE) e também foi coordenadora geral da Educação Escolar Indígena na Secretaria de Educação Continuada, Alfabetização, Diversidade e Inclusão (Secadi).

De acordo com a Dra Rita Nascimento, as escolas indígenas possuem diretrizes próprias, sendo assim:

Nessas diretrizes, as escolas indígenas são unidades que possuem seus projetos político-pedagógicos próprios, que têm suas normas e ordenamentos jurídicos específicos. A preferência para ensinar nessas escolas é de professores pertencentes àquelas comunidades indígenas, nas comunidades que têm a língua materna como a primeira língua, e o processo de alfabetização e a educação fundamental podem ocorrer na língua materna, junto com a língua portuguesa", explicou a professora (Brasil, 2018).

Segundo o Cacique Natanael, um total de cinco alunos da tribo, que já concluíram o Ensino Médio, inscreveram-se nos processos seletivos em Educação a Distância e também presencial. O processo seletivo para ingresso na Universidade Federal de Santa Maria (UFSM) ocorre a partir de uma prova diferenciada somente para indígenas. A universidade oferta vagas exclusivas para indígenas em cursos como História, Geografia, Enfermagem, Medicina, Odontologia, Direito, etc, todos os cursos escolhidos previamente pelos caciques consultados de acordo com as demandas das aldeias. Nos cursos de Medicina e de Enfermagem são ofertadas duas vagas anuais e, atualmente, cinco alunos indígenas estão cursando Medicina, sendo que três da etnia Kaingangs, uma é Guarani Caua e a outra é uma Tupiniqui. 
O Ministério de Educação e Cultura propõe algumas ações a partir da Secretaria de Educação Continuada, Alfabetização e Diversidade (SECAD), do Ministério da Educação com o objetivo de garantir a oferta de educação escolar indígena, partindo de políticas públicas:

1. Formação inicial e continuada de professores indígenas em nível médio (Magistério Indígena). Esses cursos têm em média a duração de cinco anos e são compostos, em sua maioria, por etapas intensivas de ensino presencial (quando os professores indígenas deixam suas aldeias e, durante um mês, participam de atividades conjuntas em um centro de formação) e etapas de estudos autônomos, pesquisas e reflexão sobre a prática pedagógica nas aldeias. O MEC oferece apoio técnico e financeiro à realização dos cursos.

2. Formação de Professores Indígenas em Nível Superior (licenciaturas intercultuais). O objetivo principal é garantir educação escolar de qualidade e ampliar a oferta das quatro séries finais do ensino fundamental, além de implantar o ensino médio em terras indígenas.

3. Produção de material didático específico em línguas indígenas, bilíngues ou em português. Livros, cartazes, vídeos, CDs, DVDs e outros materiais produzidos pelos professores indígenas são editados com o apoio financeiro do MEC e distribuídos às escolas indígenas.

4. Apoio político-pedagógico aos sistemas de ensino para a ampliação da oferta de educação escolar em terras indígenas.

5. Promoção do Controle Social Indígena. O MEC desenvolve, em articulação com a Funai, cursos de formação para que professores e lideranças indígenas conheçam seus direitos e exerçam o controle social sobre os mecanismos de financiamento da educação pública, bem coo sobre a execução das ações e programas em apoio à educação escolar indígena.

6. Apoio financeiro à construção reforma ou ampliação de escolas indígenas. (Brasil, 2018).

Apesar da existência de políticas públicas direcionadas aos povos indígenas, a sua efetividade é um processo lento e, um exemplo, é o curso de "Educação Indígena" na UFSM, que iniciou seu processo de formulação e suas discussões no ano de 2012. Os diálogos ocorreram em conjunto com professores da universidade e comunidades indígenas kaingang. Este curso foi aprovado pela instituição e pelo MEC, porém não existiram recursos, à época, para dar andamento no curso presencial. O projeto ficou parado até surgir a oportunidade de funcionamento em EAD (Educação a Distância). O projeto original era presencial, porém reformulou-se para o seu funcionamento em EAD. De 2012 até 2017, foram feitas reformulações no projeto original. Em 2017, abriu-se edital para o Curso em Licenciatura em Educação Indígena, prioridades para professores que estão atuando nas escolas indígenas sem formação. São 150 vagas divididas em cinco pólos de apoio presencial, ou seja, 30 vagas por polo, os mesmos "foram escolhidos priorizando a concentração dos povos kaingang no estado", segundo Cacique Natanael

\subsection{Identidade cultural: alguns teóricos e palavras do cacique}

Existe uma preocupação em valorizar a arte indígena que vem sendo passada por gerações na tribo Kaingang e esta arte também auxilia no sustento da própria tribo. A produção dos artesanatos é também meio de preservar a identidade cultural, pois a fabricação das peças artesanais são ensinamentos provenientes da ancestralidade.

Figura 2. Imagens de artesanatos feitos pelos índios.
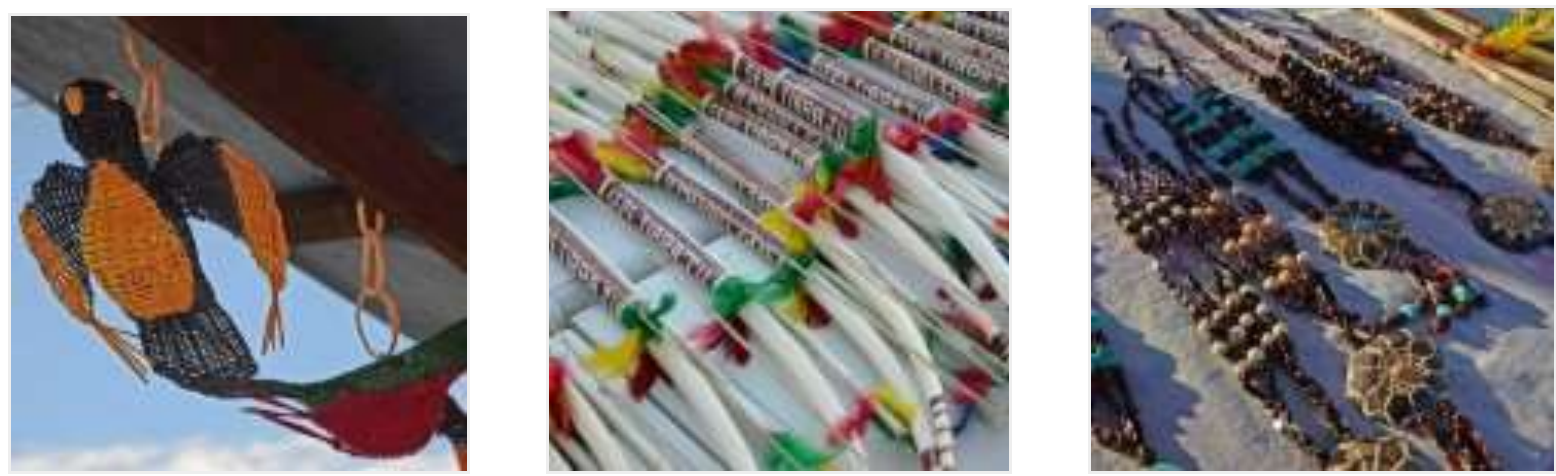

Fonte: http://centralsul.org/2013/kaingang-o-indio-em-santa-maria/ 
Nesse sentido, o artesanato produzido pelos indígenas tem por objetivos a valorização de sua cultura, haja visto que são conhecimentos repassados por gerações e, também, representa um meio de subsistência para as famílias.

Historicamente, o de cultura, surgiu em 1871, com Edward Tylor, apud Reale, Antiseri (2006, p. 20) afirmando que “[...]a cultura ou a civilização é aquele conjunto complexo que inclui o conhecimento, as crenças, a arte, [...], os costumes, e quaisquer outras capacidades e hábitos adquiridos pelo homem como membro de uma sociedade" (Reale; Antiseri, 2006, p. 20)

Franz Boas apud Reale, Antiseri (2006, p. 20) afirma que "a cultura humana se diferencia da vida animal pelo poder do raciocínio e, correlatamente pelo uso da linguagem" (Reale; Antiseri, 2006, p. 20). Em resumo, Boas propõe cultura como um conjunto de diversos fatores, como uma totalidade e que está além da biologia. Também, para este autor, a cultura representa "a totalidade das reações e atividades mentais e físicas que caracterizam o comportamento dos indivíduos que compõem um grupo social" (Pereira, 2018, p. 15).

Para Kroeber e Kluckhoohn apud Assis, Nepomuceno (2008, p. 140) “A cultura consiste em padrões, explícitos e implícitos, de comportamento e para comportamento, adquiridos e transmitidos por símbolos, que constituem as realizações distintivas dos grupos humanos [...]". Neste, inclui-se ideias tradicionais, as quais são recebidas e escolhidas historicamente e seu sentido valorativo, também a cultura na ação presente e pode condicionara ação futura. (Assis; Nepomuceno,2008).

Leslie White apud Assis, Nepomuceno (2008, p. 140) define que "Por cultura queremos dizer o conjunto de ferramentas, utensílios, língua, hábito, instituições, rituais, objetos para vários fins, sentimentos, atitudes, etc. que todos os povos possuem".

Segundo Bourdieu "a cultura é o conteúdo substancial da educação, sua fonte e sua justificação última [...] uma não pode ser pensada sem a outra" (Bourdieu, 1996, p. 43). Nesse sentido, a cultura é um elemento que sustenta o processo educacional e é importante para a formação dos indivíduos.

Stuart Hall (2011) apresenta o termo culturas nacionais como modelo caracteristicamente moderna, afirmando que

A lealdade e a identificação que, numa era pré-moderna ou em sociedades mais tradicionais, eram dadas à tribo, ao povo, à religião e à região, foram transferidas gradualmente, nas sociedades ocidentais, à cultura nacional. As diferenças regionais e étnicas foram gradualmente sendo colocadas, de forma subordinada, sob aquilo que Gellner chama de "teto político" do estado-nação, que se tornou, assim, numa fonte poderosa de significados para as identidades culturais modernas (Hall, S. 2011, p. 49).

As culturas nacionais são constituídas pelas instituições culturais, por símbolos e representações. Também é um discurso que produz sentidos sobre a/uma nação e, nesses sentidos, estão presentes as histórias, as identidades construídas, as memórias conectadas entre presente e passado (Hall, 2011).

Esses fatos representam uma realidade nas palavras do cacique Natanael:

O estado em si ele diz não pra nós muitas vezes, que a gente tem que seguir aquela regra do estado, (...) é um sistema que temos que seguir... infelizmente, mas nós lutamos, (...) porque nos somos um povo diferente...”. Estas palavras foram proferidas após conversarmos sobre a mudança da tribo que já esta ocorrendo, para a localidade conhecida como "Canudos".

De acordo com Natanael, a decisão de mudarem-se foi uma necessidade, pois apesar de terem atualmente a posse do local atual, ainda está em tramitação a decisão final. Nesse sentido, a tribo preferiu acolher um diálogo com os representantes da cidade de Santa Maria e aceitar a mudança para o local conhecido como "canudos".

Em novembro de 2018, algumas famílias da tribo já estão habitando local, construindo suas casas, a escola e também já estão plantando hortifruti para a sua subsistência. Segundo Natanael, a maior parte da terra é de mata nativa e também existe uma vertente dentro da área ocupada, esta é usada para o consumo das pessoas, 
como nós resolvemos nós mudar terminamos com a horta que tínhamos aqui... as famílias que já estão lá já estão plantando e criando galinhas, porcos... já tem plantio, o básico, feijão, milho, abobora, batata doce, mandioca... quando estivermos todos lá a ideia é fazermos tudo coletivo... as plantas que estão sendo feitas lá é tudo em coletivo, principalmente os plantio.

A tribo Kaingang adiquire sua subsistência com a venda de seus artesanatos e também alguns indígenas do sexo masculino trabalham como diaristas em alguns dias do mês para complementar a renda.

\section{Conclusão}

O desenrolar político e jurídico é um processo lento que interfere no cotidiano das tribos, acarretando insegurança e comprometendo suas práticas culturais. As políticas públicas atuais brasileiras sobre os índios ainda carecem de soluções.

A tribo Kaingang é um exemplo de luta e persistência, a pesar das dificuldades e mudança de localidade continua valorizando e preservando seus bens culturais, tem grande apreço por sua língua, sua fala e sua escrita estão presentes na pratica no seu projeto político pedagógico que segundo o cacique "quando nós criamos a escola era pra primeiro ensinar o português depois o kaingang e nós fizemos o contrário... primeiro vamos alfabetizar nossas crianças no kaingang, vamos adotar o português como segunda língua".

$\mathrm{Na}$ localidade no bairro Nossa Senhora de Lurdes, morada que esta sendo desabitada, onde existia apenas uma área de mato, a tribo Kaingang construíu sua morada, inicialmente com o uso de barracas de lona e, posteriormente, construíram uma escola e suas casas de madeira. Além disso, construíram uma horta e, aos poucos, está sendo implantado o saneamento básico. Neste final de ano de 2018, a aldeia “Três Soitas" está em processo de mudança para a localidade conhecida como "Canudos". Esta tribo leva consigo as marcas de sua cultura, suas batalhas e sua coragem para continuar com sua própria história e sua inserção no mundo contemporâneo atentando para os desafios presentes e futuros desta sociedade globalizada. Para estudos futuros acreditamos que a "nova morada" da aldeia possa ser investigada pelo viés de acesso as políticas públicas, uma vez que, deixando de serem "vistos" no espaço urbano da cidade de Santa Maria - RS, como o poder público cuida e presta assistência a que esses cidadãos têm direito.

\section{Referências}

Assis, Cássia Lobão. Estudos contemporâneos de cultura / Cássia Lobão Assis, Cristiane Maria Nepomuceno. - Campina Grande: UEPB/UFRN, 2008. 15 fasc. - (Curso de Licenciatura em Geografia - EaD). http://www.ead.uepb.edu.br/arquivos/cursos/Geografia_PAR_UAB/Fasciculos\%20\%20Material/Estudos_Contemporaneos_Cultura/Est_C_C_A05_J_GR_260508.pdf

Bourdieu, P. (1996). Razões práticas: sobre a teoria da ação. Papirus.

Brasil (2018). Instituto Brasileiro de Geografia e Estatística - IBGE. Atlas Nacional Digital no Brasil. https://www.ibge.gov.br/apps/atlas_nacional/.

Brasil (2018). Educação Indígena. Secretaria de Educação Continuada, Alfabetização e Diversidade (Secad). http://portal.mec.gov.br/setec-secretaria-deeducacao-profissional-e-tecnologica?id=12315

Brasil (2018). Quem somos. Funai. Fundação Nacional do Índio (FUNAI). http://www.funai.gov.br/index.php/quem-somos

Brasil (2018). Educadora indígena se destaca na Esplanada dos Ministérios. Portal do Ministério da Educação (MEC). http://portal.mec.gov.br/buscageral/206-noticias/1084311476/21529-educadora-indigena-se-destaca-na-esplanada-dos-ministerios

Carvalho, C. Günther, J, Spezia, K. Amorim, L. \& Weber, Y. (2018) Kaingang, o índio em Santa Maria. http://centralsul.org/2013/kaingang-o-indio-em-santamaria

GIL, A. C. (2018). Métodos e Técnicas de Pesquisa Social. <https://adm.catalao.ufg.br/up/567/o/Manual_de_metodologia_cientifica_-_Prof_Maxwell.pdf

Gadotti, M. (2018) Ecopedagogia e Educação Sustentável. http://gadotti.org.br:8080/xmlui/bitstream/handle/123456789/440/AMG_PUB_03_007.pdf ?sequence $=1 \&$ is Allowed $=\mathrm{y}$

Hall, Stuart. (2011). A Identidade Cultural na Pós-modernidade. Editora Lamparina. 
Research, Society and Development, v. 10, n. 4, e32810413970, 2021

(CC BY 4.0) | ISSN 2525-3409 | DOI: http://dx.doi.org/10.33448/rsd-v10i4.13970

Marconi, Marina de Andrade \& Lakatos, Eva Maria. (1992). Metodologia do Trabalho Científico. Editora Atlas.

Marconi, Marina de Andrade \& Lakatos, Eva Maria. (1996). Técnicas de pesquisa: planejamento e execução de pesquisas, amostragens e técnicas de pesquisas, elaboração e interpretação de dados. (3a ed.), Editora Atlas.

Nimer, Edmon (2018). Climatologia do Brasil. https://biblioteca.ibge.gov.br/visualizacao/livros/liv81099.pdf

Oliveira, M. M. (2012). Como fazer pesquisa qualitativa. (4a ed.), Vozes.

Pereira, N. Uma visão espacial e sócio demográfica da população indígena no Brasil, com base no Censo Demográfico 2010 . Atlas Nacional Digital no Brasil. https://www.ibge.gov.br/apps/atlas_nacional/

Reale, G \& Antiseri, D. (2006). História da Filosofia: De Freud à atualidade. Paulus.

Rodrigues, M. (2010). Políticas Públicas. Publifolha.

Silva, S. (2018) Dualismo e cosmologia Kaingang: o xamã e o domínio da floresta. http://www.scielo.br/scielo.php?script=sci_arttext\&pid=S010471832002000200009

Tuan, Y-F.(1983) Espaço e Lugar: a perspectiva da experiência. DIFEL.

Wiesemann, U. (2018). Os dialetos da língua Kaingáng e o Xokléng. Instituto de Antropologia Prof. Souza Marques (1978). de 2018, da Biblioteca Digital Curt Nimuendaju, de http://www.etnolinguistica.org/biblio:wiesemann-1978-kaingang 